\title{
SÓLIDAS, DÚCTEIS E LíQUIDAS: noções em mutação de "lar" e "terra natal" nos estudos da diáspora"
}

\author{
Robin Cohen ${ }^{*}$
}

\begin{abstract}
Será que a diáspora subentende a terra natal? Segundo alguns estudiosos que impulsionaram o crescimento dos estudos diaspóricos na década de noventa, essa era uma condição sine qua non do conceito. Sob a pressão dos críticos do construcionismo social que tentavam descontruir as idéias básicas de "terra natal" e comunidade, surgiram noções mais complexas e indefinidas de "terra natal" e de "lar". Essas, da realidade histórica à virtualidade pós-moderna, são aqui caracterizadas em uma escala decrescente "sólidas", "dúcteis" e "líquidas". Demonstro que essas três versões de "lar" ou "terra natal" possuem base histórica e empírica considerável, porém refuto o mero construcionismo social. Também há indícios de que as noções de "terra natal sólida" estejam recebendo cada vez mais atenção.

PALAVRAS CHAVE: migrações internacionais, diáspora, construcionismo social, lar ou terra natal, agentes de desenvolvimento.
\end{abstract}

Precisamos da terra natal para entender a diáspora? O simples fato de fazer essa indagação pareceria fora de propósito ou impossível em termos lógicos e etimológicos, à geração mais antiga de estudiosos, que impulsionou o crescimento dos estudos da diáspora na década de noventa. Diáspora significava 'dispersão', e, se os povos estavam dispersos, estava implícito um ponto de origem, mais concretamente, uma terra natal. Um dos posicionamentos mais influentes que marcaram o início dos estudos contemporâneos da diáspora foi o artigo de Safran, no número de abertura do novo periódico Diáspora (Safran, 1991, p. 83-99). Fortemente influenciado pelo caso paradigmático e latente da diáspora judaica, Safran percebeu acertadamente que muitos outros grupos

* Professorial Fellow, Queen Elizabeth House, Universidade de Oxford.

University of Oxford, 3. Mansfield Road, Oxford, OX1 3TB, UK. robin.cohen@qeh.ox.ac.uk

${ }^{1}$ Este trabalho foi apresentado em versão preliminar pela "primeira vez na Conferência sobre Dispersione, "globalizzazione" e costruzione dell'alterità: diaspore e migrazioni nel bacino del Mediterraneo ed oltre (XIX-XX secc.), Laboratorio di ricerche mediterranee di Marsala, Sicília, 19-21 de setembro de 2007. Os anais da conferência serão publicados em italiano em 2008. Está em negociação a tradução em inglês, também para 2008. étnicos também vivenciavam experiências análogas, devido talvez às circunstâncias difíceis que envolviam suas partidas dos locais de origem e, consequentemente, sua aceitação limitada nos locais de reassentamento.

Naturalmente, Safran não foi o único a reconhecer o uso difundido do conceito de diáspora, porém foi decisivo ao tentar adequá-lo cientificamente às novas demandas sociais e evitar que ele se tornasse difuso na linguagem jornalística. A experiência dos judeus continuou a influenciar a visão de Safran quanto à importância fundamental da terra natal na definição de uma das características essenciais da diáspora. Segundo ele, os membros da diáspora preservavam a memória coletiva de "sua terra natal"; idealizavam seu "lar ancestral", estavam comprometidos com a restauração da "terra natal original" e continuavam "ligados a essa terra natal” de formas diversas. Safran sustentou ainda que é possível utilizar o conceito de diáspora para descrever situações em que os membros de uma "comunidade minoritária expatriada" compartilham várias das seguintes características: 
- Eles ou seus ancestrais foram dispersos de um “centro" original para duas ou mais regiões estrangeiras.

- Retêm a memória coletiva, a visão ou o mito acerca de sua terra natal original - sua localização física, história e realizações.

- Acreditam que não são - e talvez nunca venham a ser - totalmente aceitos nas suas sociedades de acolhimento e, assim, permanecem parcialmente isolados.

- Sublimam seu lar ancestral e imaginam que, quando surgirem condições favoráveis, eles ou seus descendentes vão retornar.

- Acreditam que todos os membros da diáspora deveriam estar comprometidos com a manutenção ou restauração, segurança e prosperidade da terra natal original.

- Continuam ligados a essa terra natal de várias formas, o que contribui de modo importante para definir sua consciência e solidariedade etnocomunitárias. $^{2}$

\section{CRÍTICAS SOCIAIS E CONSTRUCIONISTAS DADIÁSPORA}

Embora a terra natal original já tenha sido fortemente enfatizada, alguns críticos, que descreverei como 'construcionistas sociais', argumentaram que Safran, o autor desse trabalho, e outros enfraqueceram o conceito. ${ }^{3}$ Influenciados por leituras pós-modernas, os construcionistas sociais tentaram decompor dois dos elementos fundamentais que anteriormente delimitavam e demarcavam a idéia diaspórica, ou seja, "terra natal” e "comu-

2 Todas as citações entre parênteses são de Safran “Diasparas in modem societies', Safran (1991, p. 8384), ênfase minha. Em resposta aos cânones normais do debate científico e social iniciado pelo autor deste artigo e por outros, Safran modificou e ampliou sua lista para chegar a um consenso significativo entre os estudiosos da diáspora. Consulte Safran (2005, p.37).

${ }^{3}$ Usei a expressão ‘construcionista social' para exemplificar uma linha de raciocínio intimamente ligada ao pós-modernismo, que sugere que a realidade é determinada pela interação social (ou intersubjetividade) e não pela objetividade (a aceitação de um mundo material ou natural) ou subjetividade (o mundo determinado pelas percepções individuais). A perspectiva tende a favorecer o voluntarismo e o agente coletivo humano em detrimento da estrutura, história e habituação. nidade étnico-religiosa”. Argumentaram, em seguida, que, no mundo pós-moderno, as identidades foram desterritorializadas e afirmadas de modo flexível e situacional; consequentemente, os conceitos de diáspora tiverem de ser radicalmente reorganizados em reação à esta complexidade. Não atribuindo o devido valor à etimologia, à história, aos limites, ao significado e à evolução do conceito de diáspora, eles tentaram desconstruir dois dos elementos fundamentais da diáspora, lar ou terra natal e comunidade étnico-religiosa. ${ }^{4}$

Este trabalho analisa o primeiro alvo dessa desconstrução: lar ou terra natal.

Embora meu trabalho anterior já tenha sinalizado determinado grau de desacoplamento entre diáspora e terra natal (Cohen, 1997; Brah, 1996, p. 192), essa ruptura foi radicalizada por Avtar Brah. (1996, p. 192). A ideia de "lar" tornou-se cada vez mais vago, quase a ponto de desaparecer. Em contraposição, seu conceito de diáspora 'faz uma critica aos discursos de origens fixas, enquanto leva em conta o desejo por um "lar", o que não é a mesma coisa que o desejo da "terra natal"'. Assim, a "terra natal” tornou-se o desejo por um “lar”, então o próprio lar foi transmutado em um lugar simbólico, embora reconhecidamente lírico. Segundo a colocação de Brah:

Onde está o lar? De um lado, "lar" é o local mítico de desejo na imaginação diaspórica. Nesse sentido, é o local do não-retorno, mesmo que seja possível visitar o território geográfico concebido como o lugar de “origem”. Por outro lado, lar é também a experiência vivida de um local. Seus sons e aromas, calor e poeira, noites aprazíveis de verão, ou a excitação da primeira caída de neve, noites geladas de inverno, céus cinzentos e sombrios em pleno meio dia... Tudo isso, mediado pela cotidiano historicamente específico das relações sociais (1996, p. 192).

Graças a essa e a outras contribuições semelhantes, atribui-se cada vez mais amplamente ao "lar" o significado de local de origem, de assentamento, ou um local nacional ou transnacional,

\footnotetext{
${ }^{4}$ Convém relembrar a percepção fundamental de Marx segundo a qual "Os homens (leia-se as pessoas) fazem a sua própria história, mas não o fazem como querem... A tradição de todas as gerações mortas oprime como um pesadelo o cérebro dos vivos". Ver Marx ([1852], 1959, p. 321).
} 
comunidade virtual imaginada (conectada, por exemplo, pela Internet), ou ainda a matriz das experiências conhecidas e de relações sociais íntimas (concordando assim com a expressão popular que diz que "lar é onde mora o coração").

Anthias colocou mais lenha na fogueira ao criticar alguns estudiosos que utilizavam o que ela descreveu como "noções absolutistas de 'origem' e 'pertencimento verdadeiro"”. ${ }^{5}$ Segundo ela, o discurso diaspórico dedicou pouca atenção às divisões internas nas comunidades étnicas ou às possibilidades de negociações culturais seletivas entre as comunidades:

...a falta de atenção dispensada à solidariedade transétnica, à de classe, aos movimentos sociais eà luta contra o racismo é bastante inquietante do ponto de vista do desenvolvimento da multiculturalidade e de noções mais abrangentes de pertencimento. Nãoé possível acomodar o discurso de antirracismo e mobilização social com uma feição transétnica (em oposição à transnacional) ao discurso da diáspora, que mantém sua dependência à "terra natal" e à "origem”, não obstante sua configuração (Anthias, 1998, p. 577).

Dois anos mais tarde, Soysal intensificou a carga. Apesar de "veneradas", as noções de diáspora privilegiam ou privilegiavam inadequadamente "o modelo de Estado-nação e as formações nacionalmente definidas, ao discorrerem sobre um processo global, como é o caso da imigração". ${ }^{6}$ Ela sustenta que os desenvolvimentos do pós-guerra

... tornam a diáspora insustentável como categoria analítica e normativa e direcionam nossa discussão às novas formas de participação, reivindicação e - pertencimento - que permanecem invisíveis aos conceitos convencionais de diáspora ou que são frequentemente consideradas insig-

${ }^{5}$ Anthias (1998, p. 557-580). Ela inclui a noção de Diáspora Global de Robin Cohen nas suas críticas, mas pensei que tivesse deixado claro que eu estava defendendo uma noção de origem mais complexa (veja Capítulos 3 sobre os africanos e 6 sobre os sikhs). Entretanto, concordo que o "pertencimento" não é dado, mas tem de ser estabelecido, mobilizado e defendido nas práticas sociais, culturais e políticas. Minhas visões são exemplificadas mais detalhadamente em Cohen (1994, cap.1, 7).

${ }^{6}$ Yasemin Nuho lu Soysal (2000, p. 1-2). Quase todos os teóricos da diáspora salientaram o fato de que a diáspora era um conceito que há muito antecedia o estado-nação e que as formações diaspóricas estavam constantemente em tensão com os Estados-nação. Ver, por exemplo, Robin Cohen (1996, p. 507-520). nificantes diante de seu peso normativo... Nessa formulação (errônea), as populações diaspóricas apegam-se à cultura e à terra natal. Do mesmo modo, suas atitudes em relação à cidadania originam-se dessa tendência de apego à terra natal e de etnicidade (Soysal, 2000, p. 2-3).

Após sua crítica inicial à diáspora, Soysal concentrou-se no caso da cidadania européia, porém retomou violentamente a aversão pelo conceito de diáspora no pósescrito, sustentando que a idéia

rompe a continuidade da experiência de imigração entre países de origem e de acolhimento, terras nativas e estrangeiras, desejos do caminho de volta e perdas - obscurecendo assim a nova topografia e as práticas de cidadania, que são multiconectadas, multi-referenciais e pós-nacionais (2000, p. 13).

A intenção fundamental dessas apreciações foi aumentar a dissociação intelectual entre as noções de "diáspora”, de um lado, e de "terra natal", "local" e "comunidade étnica", do outro. Segundo alguns autores - dos quais Anthias e Soysal são boas representantes - fica claro que a diáspora foi irremediavelmente maculada, não podendo ser encaixada em suas agendas com o objetivo almejado. A diáspora, no caso de Anthias, não poderia servir de plataforma para um movimento transétnico, sensível ao gênero e antirracista, ao passo que, no caso de Soysal, não poderia favorecer a compreensão de cidadania pós-nacional na Europa.

\section{AREAÇÃO}

Uma reação possível a essas críticas da diáspora seria considerá-las impróprias ou deslocadas, uma vez que refletiam agendas políticas que tinham pouco a ver com a história e com o significado do termo, ou com o fenômeno que procurava e continuava a explicar. Os teóricos da diáspora não reivindicaram explicar o espectro total das experiências dos imigrantes, nem fundar, por mais desejável que isso seja, um movimento progressista antirracista, nem mesmo tentar descrever padrões de sociabilidade e cidadania desvinculados do parentesco anterior ou da filiação religiosa. Em outras palavras, o 
conceito de diáspora não é uma bala mágica que possa ser usada para atingir todos os adversários.

Uma reação mais madura foi buscar possibilidades de diálogo entre os estudiosos da diáspora, os consagrados e os novos, e os críticos construcionistas sociais. Tölölyan, o mais importante estudioso da diáspora e editor do periódico Diáspora, assumiu a liderança, escolhendo cuidadosamente o caminho intermediário, embora ainda insistisse que o apego ao lugar continuava sendo importante para entender o conceito:

Os diasporistas moldados pelo discurso de globalização descrevem verdadeiras erosões do elo entre os povos definidos pelo apego ao território, fazem seu diagnóstico como sendo irreversível e imediatamente reconhecem e aprovam sua contribuição ao mundo pluralístico, multicultural e híbrido que aprovam. Os diasporistas, como é o meu caso, que desejam argumentar que o apego ao lugar era indispensável à vida diaspórica, e que pensavam assim até bem recentemente, e que, apesar do desgaste dessa forma de pensamento, continua sendo importante nos dias de hoje, devem pisar com cuidado para evitar as acusações de que estamos imitando a retórica desacreditada dos nacionalistas referente ao elo entre terra, povo e cultura, ou que permanecemos naïve [ingênuos] em relação aos espaços globais abertos durante as últimas décadas (Tölölyan, 2005, p.138-139; Brubaker, 2005, p. 5-7)

Brubaker também insistiu que, apesar da fragmentação de significado, “... três elementos nucleares continuam amplamente aceitos como constitutivos da diáspora'. (Brubaker, 2005, p. 5) São eles a dispersão (seja traumática ou voluntária e geralmente além das fronteiras do Estado), em direção à terra natal (seja uma terra natal real ou imaginária) e a manutenção das fronteiras (processos pelos quais a solidariedade do grupo é mobilizada e retida, mesmo aceitando a existência de processos contrários à erosão de fronteiras) (2005, p. 5-7).

Embora a posição do construcionismo social fosse nitidamente exagerada, sua contribuição gerou um novo questionamento e uma compreensão mais sofisticada das mudanças na relação entre "terra natal” e "diáspora”. Consequentemente, surgiram três versões principais de lar ou terra natal, as quais denomino de sólida (a necessidade inquestionável da terra natal), dúctil (uma idéia intermediária, mais complexa, da terra natal) e líquida (uma interpretação pós-moderna do lar virtual).

\section{“TERRA NATAL” SÓLIDA}

A ideia de "terra natal” está normalmente imbuída de uma carga expressiva e um pathos sentimental que parecem ser universais. Terra mãe, pátria, terra natal, torrão natal, Heimat, a terra ancestral, a busca pelas "raízes" - todas essas noções semelhantes revestem a terra natal de "uma dimensão emocional, quase reverencial” (Conner, 1996, p. 16-45; Levy; Weingrod, 2004). Muitas vezes, há uma interação complexa entre as versões masculinas e femininas de terra natal. Na interpretação feminina, a terra-mãe é vista como um seio quente, abundante, do qual os povos sugam seu sustento como coletividade. Um poeta quirguiz proclamou, de modo mítico, que a relação entre humanidade e terra natal antecede o próprio nascimento (Conner, 1996, p. 17): "Lembre-se que, mesmo antes de sugar o leite de sua mãe, você bebeu o leite de sua terra natal”. Sugerindo a mesma metáfora, dizia-se que da “Terra Prometida” da Bíblia “jorrava leite e mel”.

Em outras interpretações, o leite alvo e nutritivo da terra mãe é substituído pelo sangue dos soldados que corajosamente defendem sua pátria, sangue que alimenta o solo e solo que define sua etnogênese. Blut und Boden (terra e sangue) foi o comoventeapelo deBismarckà naçãogermânica; uma evocação reutilizada por Hitler duas gerações mais tarde. Mesmo após o ajuste constitucional liberal e democrático do pós-1945, os alemães seguem privilegiando a definição de cidadania e pertencimentojus sanguinis, a lei do sangue - com base na descendência e não no lugar de nascimento ou de residência prolongada. Assim, a terceira e a quarta geração de “alemães étnicos", originários da antiga União Soviética, muitos dos quais não falavam mais alemão, receberam prontamente a cidadania alemã em detrimento da segunda geração de turcos nascidos e educados na Alemanha. Não raro se fundem as imagens de terra pátria e terra-mãe. As concepções andrógenas britânicas de terra natal evocam o viril John Bull, personagem exemplificado nos tempos modernos pelo herói invencível da época da guerra, Winston Churchill. Elas também se originam das estórias conhecidas de Boudicca, Britânia, Rainha 
Vitória e, talvez de forma ainda mais imaginativa, da primeira-ministra Margaret Thatcher.

A ideia de "terra natal" sólida ganhou força nos últimos anos com o reconhecimento do cres-

\section{Foto 1}

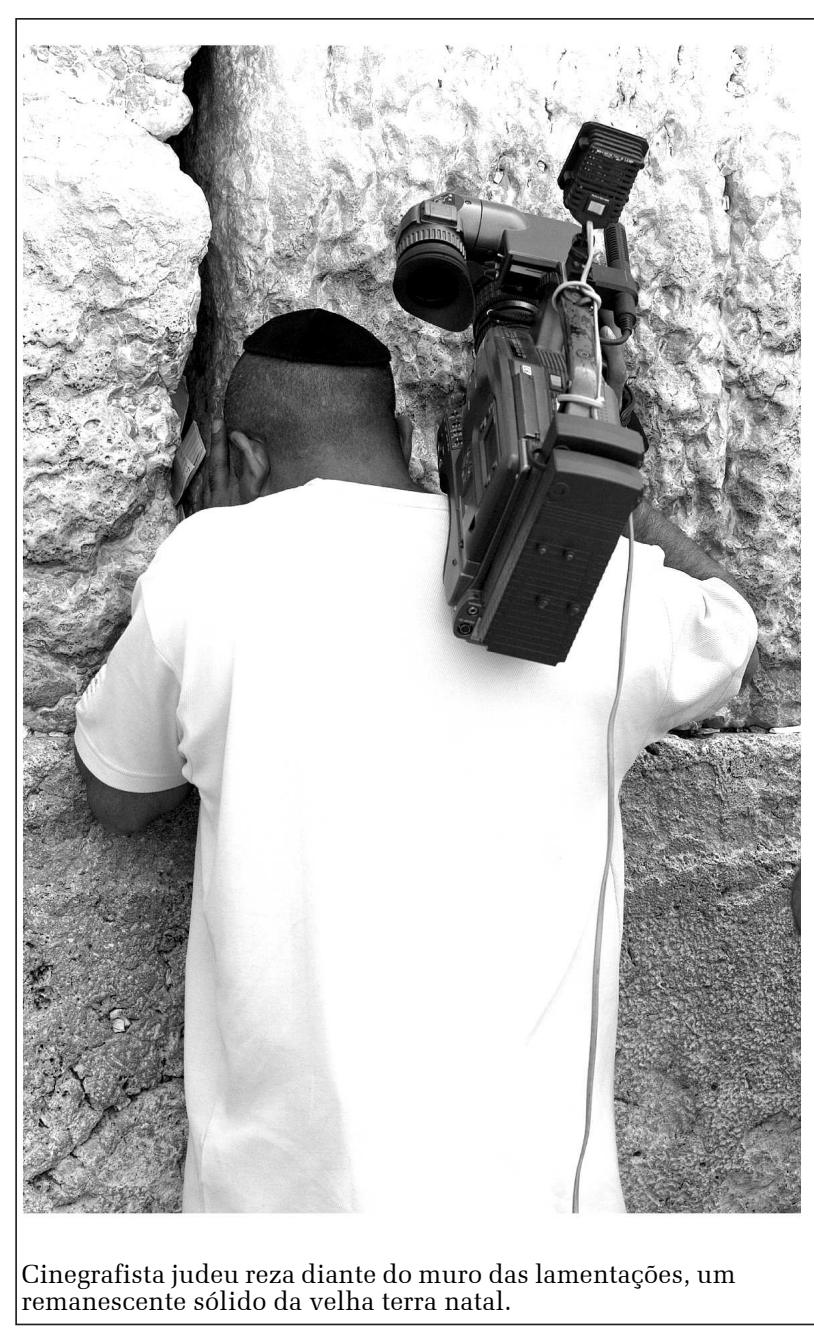

cente papel desempenhado pelas diásporas como agentes das políticas internacionais e de desenvolvimento da “terra natal”. Evidentemente, há anos que as diásporas são importantes para as políticas internacionais. Movimentos políticos como filohelenismo, sionismo, garveismo, pan-africanismo, as tentativas de criação do Khalistan e de reconstrução da Grande Armênia são representados como os únicos meios de superação da existência precária e isolada no exílio. Planos de melhoria da terra natal também foram comuns em outras diásporas. Embora nascido na China, Sun Yixian
(Sun Yat-sen) desenvolveu sua consciência política em Hong Kong e em uma comunidade chinesa no Havaí. Sua "Sociedade para Restauração da China" foi o elemento crucial na promoção do moderno nacionalismo chinês. Sem proclamar serem essas causas justas ou não, é possível observar recentemente o papel desestabilizador da diáspora Tâmil no Sri Lanka em seu apoio ao Tigres Tâmeis (Tamil Tigers), o persistente esforço da diáspora curda para estabelecer um Estado curdo e o êxito da diáspora croata em seu apoio à criação de um Estado croata independente.

Conforme ilustram os exemplos acima, o que mudou foi a desintegração da configuração bipolar das políticas internacionais após a Guerra Fria. Na atualidade, Estados, ONGs, corporações poderosas, redes de comunicação e religiões competem por poder e influência em um mundo mais complexo e pluralista. No bojo desse entrelaçamento de interesses conflitantes, as diásporas emergiram como elementos-chave nas políticas muitas vezes precárias de seus Estados de origem. $\mathrm{O}$ principal achado de uma recente coletânea de estudos sobre diásporas em conflito é que elas podem ser uma força para a estabilidade (promotoras da paz), como também uma força que amplifica ou mesmo cria conflitos (promotoras de conflito). Segundo os organizadores dessa coletânea:

Ainda é preciso estudar o envolvimento diaspórico nos conflitos; no entanto o que se pode dizer é que as diásporas desempenham 'papéis significativos e diversos' em toda a gama de atividades do ciclo de conflito (Smith; Stares, 2007, p. 9).

Outro incentivo recente à ideia de "terra natal” sólida diz respeito à intensificação do papel das diásporas como agentes do desenvolvimento econômico. Os estudiosos das diásporas sempre tiveram consciência de que as conexões diaspóricas causaram mudanças profundas nos locais de origem. Atividades agrícolas em declínio ganharam um novo alento, famílias e parentes tiveram apoio durante a velhice e pobreza, e não raro começaram a ocorrer 
mudanças mais expressivas e abrangentes. Embora esses efeitos já tenham sido há muito reconhecidos pela literatura acadêmica, somente recentemente o foram por agências de fomento, ONG’s e países mais ricos, com o objetivo de focar a ajuda no desenvolvimento. Por fim, a "ficha caiu" quando as agências de fomento constataram que as "remessas" de dinheiro enviadas pelos emigrantes do exterior aos seus paises de origem são frações significativas e crescentes do fluxo das finanças internacionais. Em 2005, em torno de 188 bilhões de dólares estadunidenses foram transferidos a países pobres, sendo que se esperava que o montante crescesse 11 bilhões de dólares estadunidenses em 2006, enquanto as remessas totais de países ricos e pobres totalizavam 268 bilhões de dólares estadunidenses. Esses números são provenientes de um relatório do Banco Mundial, cujos autores ainda salientam que esses totais refletem apenas as transferências formalmente autorizadas. Acrescentam que:

... os fluxos não registrados por intermédio de canais informais podem acrescentar 50 por cento ou mais aos fluxos já registrados. Com a inclusão dos fluxos não registrados, o volume real dessas remessas torna-se maior que o fluxo de investimentos externos diretos e duas vezes maior do que a ajuda oficial recebida pelos países em desenvolvimento (Mohapatra; Ratha; Xu, 2007, p. 3).

As agências de fomento não somente reconheceram que os atuais volumes de transferência de recursos são massivos, mas que a canalização por intermédio das diásporas é preferível ao envio de recursos aos governos dos países pobres, seja por causa da sua ineficiência, seja por causa da sua corrupção. Por razões práticas as ambiguidades entre "lar" e "terra natal" foram abolidas, na medida em que os estudiosos da diáspora inauguram um novo campo de estudos aplicados da diáspora.

\section{“TERRA NATAL” DÚCTIL}

Gostaria agora de abordar a minha categoria intermediária. Mesmo no caso prototípico da diáspora judaica, a idéia de terra natal sólida parece estar perdendo força. Curiosamente, William
Safran, cujo trabalho inicial sobre a necessidade de "terra natal" já foi anteriormente discutido, adota agora um uso mais flexível (dúctil) de terra natal. Baseando-se, até certo ponto, em pesquisas atitudinais, Safran argumenta que, no caso de Israel, de um lado, e dos europeus e judeus americanos, do outro, os elos entre o país de acolhimento e a terra natal estão ficando mais tênues (Safran, 2005, p. 193-200). Dentre os membros da diáspora judaica que vivenciam o processo de "dessionismo”, estão incluídos os grupos que Safran denominou de secularistas, socialistas, investidores potenciais em Israel, fiéis não-ortodoxos, judeus educados na cultura ocidental, ideólogos da esquerda, acadêmicos e outros desiludidos com as expressões do poder do Estado de Israel. O outro lado da moeda é que, não obstante as explosões intermitentes do anti-semitismo, as condições de vida na diáspora são atraentes e seguras e não estimulam uma maior identificação com Israel.

Surpreendentemente, os proto-sionistas também promovem acampamentos de verão nos quais, em assentamentos rurais seguros nos Estados Unidos, acontecem as aliya virtuais (migrações "para" Israel) completas, com bandeiras de Israel, aulas de hebraico, rituais religiosos, simulações da vida em um kibutz e acesso a outros aspectos atraentes da cultura popular israelense (Safran, 2005, p. 199-200). Como o próprio Safran reconhece, o conceito mais rígido de terra natal cedeu lugar a noções mais maleáveis de "um lar encontrado" na diáspora e de um "lar virtual" em um acampamento de verão - talvez alimentadas por visitas ocasionais a Israel, ao invés de residir ali permanentemente. Gostaria de acrescentar que o inesperado, porém considerável fluxo de israelenses, veementemente desaprovado pelos sionistas, para os Estados Unidos e Europa, também modificou substantivamente a relação entre a terra natal e a diáspora judaica (Gold, 2002).

Gostaria também de frisar dois exemplos intrigantes ambos centrados em Bombaim. O primeiro refere-se aos sindis, historicamente estabelecidos na área atualmente definida como a província mais ao sul do Paquistão. O Sind teve exis- 
tência prévia independente, porém foi governado pelos britânicos por pouco mais de cem anos, de 1843 a 1947. A área é atravessada pelo rio Indo, que é navegável e que desemboca no outrora "Mar Sindi” (hoje Mar Arábico); os antigos marinheiros gregos, persas, árabes e sindis estavam ligados a uma rede de comércio de longo alcance muito antes da chegada dos europeus Ali Shah, (1997, p. 43). A província é estrategicamente importante, com uma fronteira extensa com a Índia e um porto de importância vital que conecta o Sind à Ásia Central e à vastidão do comércio e negócios da região do Golfo Pérsico e do Oceano Indico.

Falzon iniciou o estudo da história dos sindis (Fazon, 2003, p. 602-683), concentrando-se especialmente no caso dos sindis hindus (a maioria dos quais reconhece os ensinamentos do Guru Nanak, o primeiro guru do siquismo, embora permaneçam ligados ao hinduísmo). A primeira onda diaspórica surgiu no começo da ocupação britânica e constituiu-se na diáspora clássica de natureza comercial. A segunda, e muito mais numerosa

Foto 2

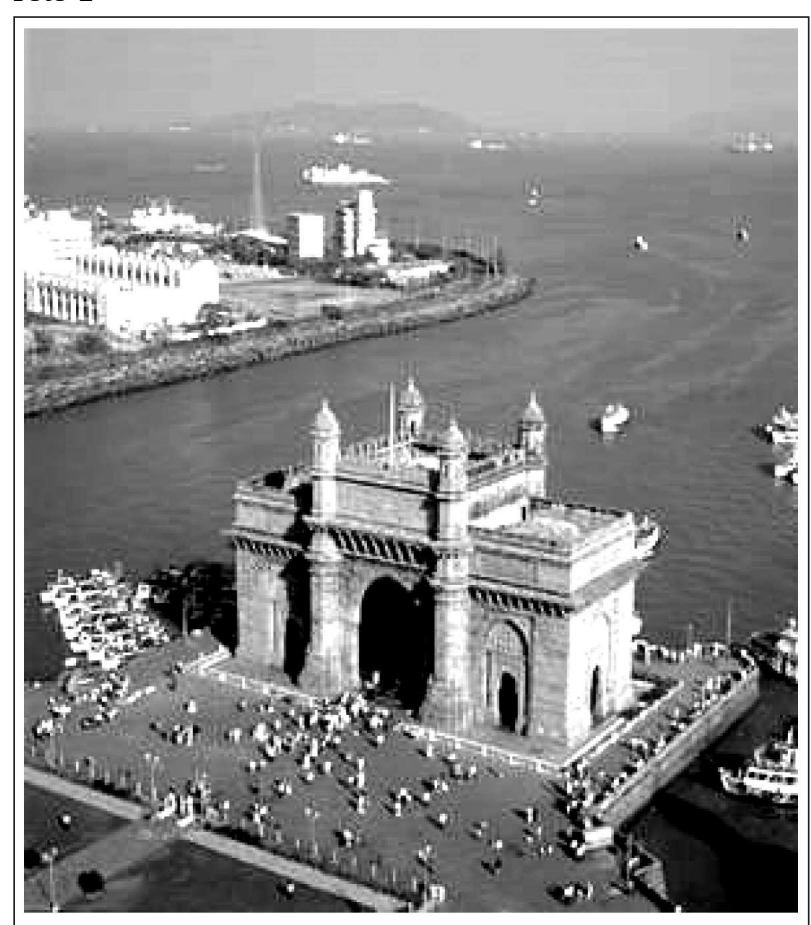

Porto de Mumbai (Bombaim) ao qual chegaram muitos dos refugiados sindis provenientes do Paquistão na época da divisão. Bombaim é hoje a terra natal dos deslocados, muito embora as ligações férreas com Karachi ainda precisem ser restauradas. onda, acompanhou o fim da terrível dominação e divisão britânicas. Os sindis hindus, que se encontravam no Paquistão muçulmano, deslocaramse em massa para a Índia, especialmente para Bombaim e sua cidade-satélite, Ulhasnagar (renomeada Sindhunagar, em razão da forte presença dos sindis). Já existiam fortes laços administrativos, educacionais e comerciais com Bombaim, e a saída marítima para lá era o rumo mais seguro para a sequência de ações dos refugiados.

A Índia tem sido generosa com os sindis, e a comunidade deles em Bombaim é amplamente considerada como politicamente integrada e economicamente bem sucedida. A evidência emblemática desse sucesso foi a eleição de L. K. Advani para o cargo de vice-primeiro ministro da Índia e a eminência (às vezes cercada de publicidade) dos incrivelmente ricos irmãos Hinduja. À semelhança dos irmãos Hinduja que alçaram vôo, muitos sindis indianos seguiram adiante, mudando-se e estabelecendo residência em aproximadamente 100 países distantes, às vezes ligados aos comerciantes sindis pioneiros. Será que os sindis formaram uma diáspora desterritorializada? Falzon argumenta que “.... a noção de uma terra natal (distante) ainda permanece central no imaginário diaspórico dos sindis hindus", embora a idéia de resgatar a "terra natal" do Sindhi histórico seja cada vez mais considerada como uma impossibilidade política. Em contraposição, os benefícios do estabelecimento de uma rede transnacional economicamente bem sucedida, centrada em Bombaim, são visíveis a todos, exceção feita aos poucos "empreendedores culturais", que saudosamente esperam pela terra natal perdida (Falzon, 2003, p. 668-669). Alguns estão até mesmo prontos para argumentar que a divisão de 1947 foi uma "dádiva mascarada”, enquanto um poeta declama extasiado:

O Sindhi! Que Deus esteja consigo

Que você espalhe felicidade

Onde quer que encontre o seu povo, chame esse lugar de lar.

Onde quer que encontre sindis, chame o lugar de seu Sind (2003, p. 662). 
Embora a população sindi de Bombaim permaneça numerosa, os sindis diaspóricos, em muitos casos, possuem ali um segundo lar e para lá retornam a fim de desfrutar os prazeres conhecidos da cidade, encontrar amigos e familiares, participar do próspero mercado de casamentos de seus filhos e fechar negócios com novos e velhos parceiros comerciais. Como Falzon explica, Bombaim tornou-se o "coração cultural" de uma diáspora desterritorializada:

Reputação comercial, narrativas pessoais, indi-
cadores de riqueza, virtudes e inúmeros outros
aspectos pessoais e mais significativamente, fa-
miliares chegam periodicamente em Bombaim
dos quatro cantos do globo, e, por intermédio da
interação ocorrida na cidade, são re-exportados
para as várias localidades da diáspora. A presen-
ça na cidade de hotéis cinco estrelas, restauran-
tes sofisticados e empório de saris são uma exce-
lente oportunidade para o tipo de consumo ex-
travagante pelo qual os sindis são estereotipados,
embora não de modo injustificado, independen-
temente de onde estejam (2003, p. 673).

Bombaim (renomeada Mumbai pelos nacionalistas) é notoriamente, como se sabe, uma cidade cosmopolita, a cidade de intelectuais diaspóricos famosos, como, por exemplo, Salman Rushdie, os quais celebram a diversidade da cidade. Os personagens principais de seu romance Oúltimo suspiro do mouro foram inspirados nos judeus Cochin (da região de Cochin, sul da Índia) e nos cristãos portugueses da cidade. A cidade tornou-se o "lar", ou lugar de passagem de muitos povos diaspóricos. $\mathrm{Na}$ Rua Meadows, encontra-se uma igreja armênia edificada em 1776. Em 1864, observou Ewald: “... mais da metade dos dois mil africanos (provavelmente sub-registrados) em Bombaim ganhavam seu sustento como marinheiros ou em atividades relacionadas ao trabalho marítimo" (Ewald, 2000). Emfunção dessa diversidade, não é de se estranhar, portanto, que em Bombaim se encontre significativa comunidade zoroastriana conhecida como parses. Os parses tornaram-se parte consagrada do cenário da cidade já em 1640, porém só em 1673 a Companhia Britânica das Índias Orientais consentiu que seus rituais funerários, nos quais os corpos são entregues aos abutres para serem devorados, fossem realizados na Torre do Silêncio, na Montanha de Malabar.
Como Hinnells explica em seu estudo monumental da diáspora zoroastriana, em Bombaim, os parses tornaram-se a principal referência cultural e religiosa da comunidade em todo o mundo, a partir do século dezoito em diante (Hinnells, 2005, cap. 2). Ele levou em consideração os exemplos de outras onze comunidades zoroastrianas (em Hong Kong, Leste da África, Grã-Bretanha, Europa Continental, EUA, Canadá e Austrália), mostrando como os padrões endogâmicos, mobilidade social e casamento tardio reduziram gradualmente essa antiga comunidade para aproximadamente cem mil membros. Todavia a principal ameaça aos zoroatrianos manifestou-se na própria terra natal, o Irã (a antiga Persa), onde a emigração e conversão, desde a revolução islâmica de 1979, reduziram a comunidade para aproximadamente vinte e dois mil membros. Estabelecidos há séculos naquele país, os zoroastrianos ocuparam uma vez o trono persa, antes de serem expulsos pela dominação muçulmana em 652 d.C. Apesar da permanência de algumas relíquias sagradas, tais como o templo Chak-chak no Irã, que ainda é local de peregrinação, a diáspora tornou-se quase que completamente desterritorializada, com suas principais religiões e referências culturais ancoradas em Bombaim.

\section{“LARES” LÍQUIDOS}

Vivemos o mundo da "modernidade líquida”, afirma Zygmunt Bauman, no qual "testemunhamos a represália do nomandismo contra os princípios de territorialidade e de povoamento" (Bauman, 2003, p. 13). A evocação da liquidez e do movimento constante faz lembrar a citação de Marx e Engels no Manifesto Comunista: "Tudo o que é sólido se desmancha no ar e tudo o que é sagrado se profana". Marshall Berman, acadêmico literário, faz reverberar a citação:

Ser moderno é experimentar a existência pessoal e social como um torvelinho; ver o mundo e a si próprio em perpétua desintegração e angústias, ambiguidade e contradição: é fazer parte de um universo em que tudo o que é sólido se desmancha no ar (Berman, 1982, p. 345-346). 
Será que podemos dilatar ainda mais os sentidos históricos do conceito de lar diaspórico para incluir novas formas de mobilidade e deslocamento e a construção de novas identidades e subjetividades? Proponho que adotemos a expressão "diáspora desterritorializada" para incluir as feições de uma série de experiências diaspóricas incomuns. ${ }^{7} \mathrm{Nes}-$ ses exemplos, supõe-se que os grupos étnicos perderam os pontos convencionais de referência territorial, tornando-se, de fato, culturas móveis e multilocalizadas com lares virtuais ou incertos.

Pode-se facilmente pensar em certos grupos populacionais como culturas nômades, uma vez que eles sempre tiveram uma característica errante. Imediatamente vêm à mente os tuaregues, beduínos, san, qashquai, maasai e bérber. Contudo, se o "lar" sempre esteve em movimento, é questionável que o termo "diáspora" possa acrescentar algo de útil ao uso tradicional da expressão "nômade", a não ser fornecer um novo rótulo. Um exemplo bem mais intrigante é o dos romas (ciganos), que possuem uma narrativa de etnogênese na Índia, mas que perderam qualquer vínculo sistemático com o subcontinente indiano. Considerálos diaspóricos é um desafio estimulante. ${ }^{8}$ Todavia, o caso mais importante de uma diáspora desterritorializada, com um "lar líquido", é a dos povos caribenhos.

A população principal do Caribe deslocouse várias vezes e continua suas tradições migratórias - da África, dentro do próprio arquipélago caribenho, e até muito além. Os primeiros povos assentados do Caribe, os caraíbas e arauá, não conseguiram sobreviver às glórias da civilização ocidental-quase todos morreram em consequência das conquistas, do excesso de trabalho e de doen-

\footnotetext{
7 Adotei a expressão "diáspora desterritorilizada" na segunda edição revisada de Global diasporas: an introduction (Diásporas Globais; uma introdução) (disponível em 2008), para substituir "diásporas culturais", usada na primeira edição do livro, mas que, por não ser suficientemente precisa, gerava equívocos.

${ }^{8}$ Sou grato à minha colega de Warwick, Paola Toninato, que me falou da importância da literatura romana no desenvolvimento da consciência diaspórica. O seu artigo a ser publicado sobre o tema é muito útil É ampla a
literatura sobre os romãs ou ciganos; uma coletânea bem especializada é a da Universidade de Leeds. Disponível em: www.leeds.ac.uk/library/spcoll/spprint/26600.htm
}

ças. ${ }^{9}$ Praticamente todos os que se estabeleceram no Caribe vieram de outro lugar - escravos africanos do oeste da África, colonos europeus brancos, agricultores e administradores vindos da Europa, indianos que chegavam como trabalhadores com contrato de servidão e comerciantes do Oriente Médio. Geralmente, as sociedades de colonos e imigrantes são vistas como pontos de chegada, e não de partida; locais de uma coletividade renovada, e não de dissolução, emigração ou dispersão.

Foto 3

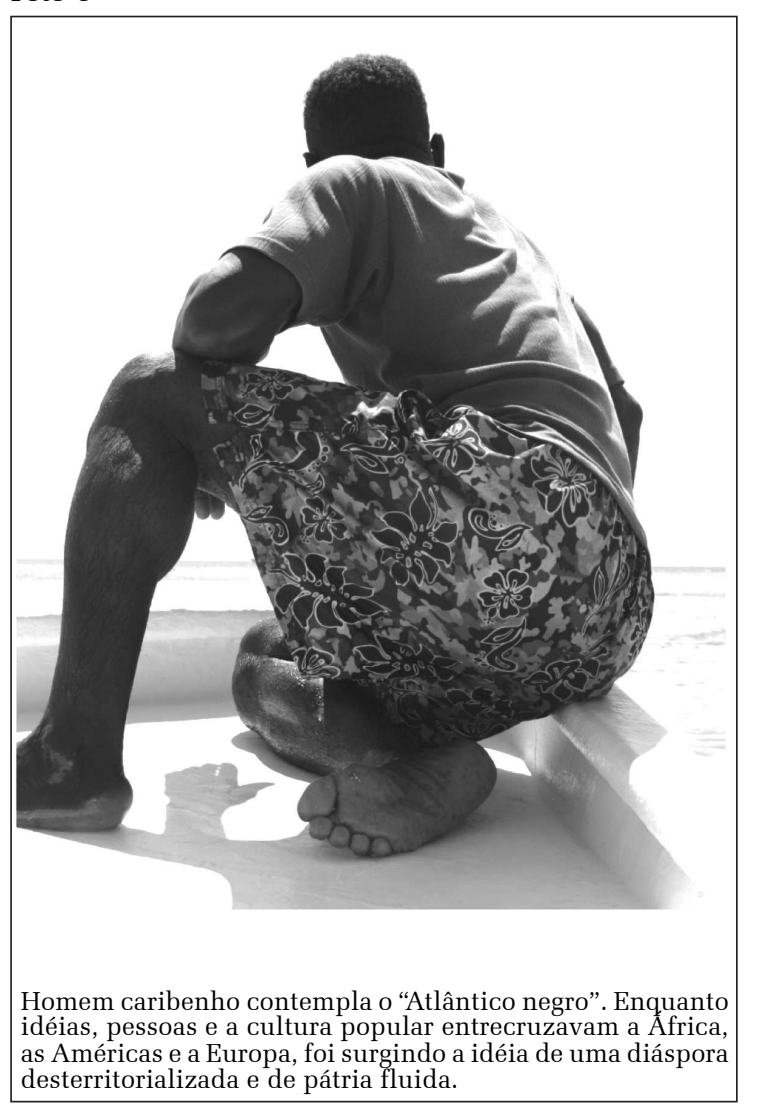

Não obstante, os povos caribenhos podem ser considerados um caso exemplar de diáspora desterritorializada. Isso se deve, em primeiro lugar, à sua história comum de dispersão forçada, devido ao comércio de escravos - ainda compartilhada por quase todos os povos de descendência

${ }^{9}$ Em uma recente visita à ilha (2007), fiquei muito satisfeito em saber que cerca de três mil pessoas em Dominica reivindicam serem caraíbas e buscam obter certa autonomia territorial. Ainda que muitas dessas pessoas possuam uma tradição mista, sua identificação cultural com os caraíbas é bastante marcante. 
africana, a despeito de sua subsequente libertação, povoamento e cidadania em vários países do Novo Mundo e mais além. Até certo ponto, é uma questão de visibilidade. Diferentemente do caso dos judeus e dos armênios, cuja perda das características físicas mais evidente é possível, na Europa e América do Norte, com a exogamia, nos descendentes de origem africana, a cor da pele normalmente permanece, apesar da exogamia, como um traço característico durante duas, três ou mais gerações. A utilização da cor da pele, em muitas sociedades, como símbolo de status, poder e oportunidade, torna impossível a qualquer pessoa de descendência africana evitar a estigmatização racial. Conforme um escritor britânico formulou de modo inequívoco: "nossa imaginação está condicionada por uma proximidade duradoura com os regimes de terror racial” (Gilroly, 1993, p.103).

Paul Gilroy, em seu livro Atlântico Negro, realizou a tentativa intelectualmente mais ambiciosa de definir o "lar fluído" caribenho (1993). Ele entende que a consciência da diáspora africana se forma a partir de uma complexa mescla cultural e social entre África, Europa e Américas. Contudo, o resultado não é a uniformidade cultural, mas sim o reconhecimento de "multiplicidades transnacionais e inter-culturais”. Evidentemente, deve existir algum grau de unidade entre as culturas diaspóricas dos africanos das bordas do Atlântico, para que possam ser consideradas um impulso compartilhado e uma forma de consciência. Essa cultura emergente é classificada como "o Atlântico Negro”, um verdadeiro lar líquido.

De fato, uma idéia de África permaneceu no imaginário do Caribe francofônico e anglofônico. Em se tratando de intelectuais como Césaire, a idéia de retorno era subconsciente, figurativa e simbólica (Césaire, 1956). No Caribe anglófono, a idéia de vínculos com a África disseminou-se não só entre os intelectuais, alcançando as massas - graças aos movimentos garveista e rastafári. Entretanto, a idéia de África era uma invenção, uma Etiópia mental que raramente se traduzia em um movimento verdadeiro de retorno ou de associação permanente. Os vínculos reais não eram com a África, mas com os outros povos dispersos de origem africana. Essa questão foi especialmente significativa em relação à cultura popular - música, literatura, carnaval, artes visuais e cênicas e formas de linguagem - na qual ocorria considerável polinização cruzada de idéias, imagens e conceitos que singraram os oceanos e atravessaram as nuvens, em perfeita sincronia com a tese do Atlântico negro. As fronteiras da região estendem-se além do Caribe - tanto na consciência, como também na conduta social, nos padrões de migração e na realização dos povos caribenhos nos locais de estabelecimento e permanência temporária.

Se remontarmos à história das diásporas, encontraremos outras formas de "lar líquido" nas conexões entre religião e diáspora. A diáspora passou a fazer parte da história judaica com a tradução da Bíblia para o grego, sendo que, no primeiro século d.C., segundo Bauman, os cristãos adotaram e alteraram seu "significado soteriológico de acordo com a escatologia cristã”. Ele continua:

O Novo Testamento utiliza três vezes o substantivo diáspora e o verbo diaspeirein. Sem entrar em detalhes quanto aos usos complexos, os escritores das diferentes histórias e Epístolas interpretaram a Igreja primitiva "como uma comunidade peregrina, de permanência provisória e dispersa, interpretando-a como sendo o povo escatológico de Deus”. Os cristãos, vivendo em dispersão sobre a terra, serviriam de "sementes", disseminando a mensagem de Jesus. A verdadeira pátria cristã, no entanto, estava na "cidade celeste de Jerusalém”, a aspiração da peregrinação cristã. ${ }^{10}$

Algumas comunidades cristãs comportaram-se exatamente segundo a tradição que Bauman descreve. Os menonitas (cristãos anabatistas do século dezesseis) são um bom exemplo. A dispersão ocorreu em decorrência de cisões internas (não raro em torno de diferenças teológicas aparentemente sutis), em reação à perseguição aberta ou em resposta às tentativas realizadas pelos Estados

${ }^{10}$ Martin Baumann (2000, p. 319). A longa citação dentro do bloco de citação é da tese de doutorado de Ảiyenakun P. J. Arowele, citada integralmente no artigo de Baumann. Sou grato à Martin Bauman, Steven Vertovec e Stéphane Dufoix, os quais de várias formas aprimoraram diretamente as conexões entre comunidades religiosas e diáspora. 
de submeter as comunidades religiosas ao sistema de tributação e colocá-las sob seu controle. Para aqueles que acreditavam unicamente no Reino de Deus, propagando a semente do cristianismo em outras partes do mundo, era o óbvio a ser feito. Os menonitas acabaram, em grande parte, em pequenas comunidades rurais, dispersando-se em 51 países em toda a África, Europa e Américas. Alain Epp Weaver, teólogo menonita, argumenta que há (ou que, ao menos, deveria existir) um paralelo estreito entre cristãos e judeus. Ambos, sustenta o autor, cometeram graves equívocos quando se subordinaram ao poder do Estado. No caso dos cristãos, o estabelecimento do cristianismo como religião oficial do Estado pelo imperador romano Constantino (280-337 a.C.) e, no caso dos judeus, a criação do estado de Israel. Deixando-se envolver pelas instituições temporais, judeus e cristãos insensatamente abandonaram suas missões espirituais. Weaver argumenta que ambos "são chamados a uma fé diaspórica e de exílio que incorpora uma política alternativa em meio às Babilônias do mundo" (Weaver).

Ninian Smart descreve, embora de forma sucinta, o destino das religiões diaspóricas nos tempos globais (1987, p. 288-297). A base de sua argumentação é que, com o ritmo acelerado da conectividade, especialmente no tocante às viagens de longa duração e de baixo-custo, até mesmo comunidades religiosas pobres podem manter contato com os principais epicentros de suas religiões: os judeus com Jerusalém e o Muro das Lamentações, os católicos com Roma e Lourdes, os hindus com Varanasi e Ganges, os siques com Amritsar e o Templo de Ouro, os muçulmanos com Meca e a Caaba, e assim por diante. Os contatos frequentemente tomam a forma de peregrinação aos lugares religiosos importantes - não raro a chama da paixão religiosa é alimentada pela longa separação seguida de formas ritualizadas de conectividade como, por exemplo, o Hajj. O Hajj, o quinto pilar do Islã, é fonte de inspiração e união para a comunidade islâmica mundial, os Umma. Os fiéis com saúde e que podem arcar com os custos da jornada são obrigados a viajar a Meca ao menos uma vez em suas vidas: aproximadamente dois milhões o fazem a cada ano. De vez em quando, a multidão entusiasta lota os locais sagrados. Em 2006, trezentos e quarenta e cinco peregrinos perderam suas vidas durante o Hajj, em uma debandada motivada pelo pânico, próximo aos três pilares diante dos quais o demônio surgiu perante Abraão e onde os fiéis são estimulados a atirar pedras.

As peregrinações cristãs também experimentaram o ressurgimento massivo com a redução dos custos e a maior acessibilidade do transporte internacional. ${ }^{11}$ Possivelmente, o exemplo mais famoso, nesse caso, é o de Lourdes, pequena cidade nos Pireneus franceses. Anualmente, milhões de pessoas viajam a Lourdes (Smither, 2004). Com uma população permanente de apenas quinze mil habitantes, a cidade possui duzentos e setenta hotéis e é a segunda francesa em número de leitos, perdendo apenas para Paris. Como sempre acontece nos locais de peregrinação, a aura religiosa que envolve Lourdes surgiu da aparição misteriosa de uma figura religiosa. No caso em questão, alega-se que uma jovem de 14 anos presenciou dezoito aparições da Virgem Maria em 1854. Acredita-se que as águas de Lourdes sejam milagrosas, e muitos dos doentes (alguns em cadeiras de roda ou em macas) chegam à cidade na esperança de conseguir uma das sessenta e seis curas milagrosas reconhecidas oficialmente. As peregrinações também adquiriram novos significados em outras religiões. Um número cada vez maior de budistas e taoístas retorna ao Monte Tai, no nordeste chinês, onde santuários foram vandalizados pela Guarda Vermelha maoísta, porém restaurados após 1976. Sacerdotes xintoístas promovem pelo menos quinze festivais anuais para acolher bem os peregrinos em Taisha, Japão.

${ }^{11}$ Esta parte baseia-se em Global Sociology de Robin Cohen e Paul Kennedy, Basingstoke: Palgrave, 2007, cap.16. Trad. Sociologia Global. 


\section{CONCLUSÃO}

Se analisarmos criticamente os usos diversos das idéias de "lar" e "terra natal" nos estudos das diásporas, encontraremos uma boa base empírica e histórica para as três noções aqui defendidas - sólida, dúctil e líquida. Os mitos de origem comum são frequentemente territorializados, enquanto que os mitos altamente sentimentais, porém poderosos, do "país ancestral" são reconhecidos. Na "terra prometida" dos judeus jorrava leite e mel. Os cedros antigos e a fragrância de hortelã no Monte Líbano podem ser acionados para dissipar o odor dos cadáveres produzidos pelas recentes guerras civis e invasões. As construções imponentes no Zimbábue permanecem como prova de que os africanos uma vez possuíram civilizações superiores e grandes impérios, o que constitui uma clara refutação do seu freqüente status inferior na diáspora. Os assírios em Londres e Chicago comentam seu elo com a grande civilização da Mesopotâmia, enquanto seus arquirrivais, os armênios, organizam dispendiosas expedições arqueológicas a fim de escavar seus palácios e santuários.

Observamos também que, em alguns casos, a "terra natal" cedeu lugar a uma noção mais dúctil, que pode ser deslocada, como no caso dos sindis e parses de Bombaim, ou de algum modo atenuado como no caso da dessionização. Presenciamos também que "lares virtuais", desterritorializados e líquidos podem ser construídos por intermédio de ligações culturais, como é o caso caribenho, pela substituição de monumentos sagrados, rios, ícones e santuários pela pátria, como nas diásporas religiosas. Talvez seja importante salientar que a África não desapareceu do imaginário caribenho, da mesma forma que os sindis e parses hindus ainda se lembram do Sindi e da Pérsia, não importa o quão longinquamente. Em vez de um processo completo de apagamento, as condições na terra natal tornaram-se tão hostis (e as condições relativamente propícias em partes da diáspora tão atraentes), que a recuperação da terra natal foi sendo adiada indefinidamente e substituída por novos centros de realização religiosa, cultural e econômica.
Como podemos fazer a mediação desses três usos? Uma forma viável de lidar com essa intensificação é permitir que prevaleça o critério autodeclaratório. Pátria e terra natal é o que dizemos que são. Quem somos nós para contestar? Outra estratégia é seguir a tática adotada por Procrustes, na Grécia antiga, que oferecia hospitalidade aos transeuntes em sua cama de ferro. Para adaptá-los perfeitamente à cama, ele alongava os mais baixos e decepava os membros superiores dos mais altos. Por analogia, poderíamos adotar uma série de critérios absolutamente rígidos, segundo os quais todas as noções de "lar" ou "terra natal" teriam de se adequar, antes que lhes fosse permitido deitar em nossa cama conceitual. Rejeitando as duas estratégias, continuo a insistir no embasamento empírico e histórico de qualquer conceito de "lar" ou "terra natal". As críticas pós-modernas, na sua maior parte pouco fundamentadas, insinuam a existência de um movimento de mão-única, que vai das noções sólidas de terra natal às noções líquidas de lar. Todavia, como já argumentei, a categoria intermediária de dúctil continua sendo importante, e as versões de terra natal sólida recebem apoio cada vez maior, enquanto as diásporas se mobilizam para desempenhar um papel de destaque nas políticas nacionais e internacionais e no desenvolvimento econômico e social de seus territórios de origem.

Tradução: Maria Lavínia Sobreira de Magalhães e Daniel Sobreira de Magalhães

Revisão Técnica: Eduardo Paes-Machado

(Recebido para publicação em setembro de 2008) (Aceito em novembro de 2008)

\section{REFERÊNCIAS}

ALI SHAH, Mehtab. The foreign policy of Pakistan: ethnic impacts on diplomacy. London: I.B. Tauris, 1997. p. 43.

ANTHIAS, Floya. Evaluating “diaspora”: beyond ethnicity, Sociology, London, v. 32 n.3, ago., p. 557-580, 1998. Disponível em: www.yorku.ca/gmcr/race_gender_class/ settlement_files/Anthias1998.pdf 
BAUMAN, Zygmunt. Liquid modernity. Cambridge: Polity Press, 2000. p. 13.

BAUMANN, Martin. Diaspora: genealogies of semantics and transcultural comparison, Numen, Germantown, NY, v. 47 , n. 3 , 2000. p. 319 .

BERMAN, Marshall. All that is solid melts into air: the experience of modernity. New York: Simon and Schuster, 1982. p. 345-346.

BRAH, Avtar. Cartographies of diaspora: contesting identities London: Routledge, 1996. p.192.

BRUBAKER, Rogers. The "diaspora" diaspora. Ethnic and Racial Studies, London, v. 28, n. 1, p. 5-7, 2005.

CÉSAIRE, Aimé. Return to my native land. Harmondsworth: Penguin, 1956.

COHEN, Robin. Global diasporas: an introduction. London: UCL Press, 1997.

Diasporas and the nationstate: from victims to challengers. International Affairs. v. 72, n. 3, jul., p. 50720, 1996. Disponível em: www2.etown.edu/vl

Frontiers of identity: the british and the others. London: Longman, 1994. Cap.1, 7.

CONNER, Walker. The impact of homelands upon diaspora. In: SHEFFER, Gabriel (Ed.) Modern diasporas in international politics. London: Croom Helm, 1996. p. 16-45.

EWALD, Janet J. Crossers of the sea: slaves, freedmen, and other migrants in the Northwestern Indian Ocean, c.1750-1914. American Historical Review, v. 105, n. 1, 2000. Disponível em: www.historycooperative.org/ journals/ahr/105.1/ah000069.html

FALZON, Mark-Anthony. Bombay, our cultural heart: rethinking the relation between homeland and diaspora. Ethnic and Racial Studies, University of Malta, v. 26, n. 4, p.602-683, 2003. Disponível em: w w w. i n f o r m a w o r l d.com / s m p p content $\sim$ content $=$ a713766604 $\sim \mathrm{db}=$ all

GILROY, Paul. Small acts: thoughts on the politics of black cultures London: Serpent's Tail, 1993. p.103.

. The black Atlantic: modernity and double consciousness. London: Verso, 1993.

GOLD, Steven J. The Israeli diaspora. London: Routledge, 2002.

HINNELLS, John R. The zoroastrian diaspora: religion and migration Oxford: Oxford University Press, 2005. Cap. 2.
LEVY, André; WEINGROD, Alex (Ed.) Homelands and diasporas: holy lands and other spaces. Stanford: Stanford University Press, 2004

MARX Karl. The Eighteenth Brumaire of Louis Napoleon. In: FEUER,Lewis S. (Ed.) Marx and Engels: basic writings on politics and philosophy New York: Anchor Books, [1852], 1959. p. 32.

MOHAPATRA, Sanket; RATHA, Dilip; XU, Zhimei. Migration and development Brief 2. Development prospects group, migration and remittances team 1,(remittance trends). Washington, DC: World Bank 2007, p. 3.

SAFRAN, William. The Jewish diaspora in a comparative and theoretical perspective, Israel Studies, [S.l.], v. 10, n. 1, p. 37,2005 .

The tenuous link between hostlands and homeland: the progressive dezionization of western diásporas. In: ANTEBY-YEMENI, Lisa; BERTHOMIERE, William; SHEFFER, Gabriel (Ed.) Les diasporas: 2000 ans d'histoire. Rennes: Presse Universitaires de Rennes, 2005. p. 193-208.

. Diasporas in modern societies: myths of homeland and return, Diaspora, v. 1, n. 1, p. 83-99, 1991.

SMART, Ninian. The importance of diasporas. In: SHAKED, S.; SHYULMAN, D.; STROUMSA, C. G. (Ed.) Gilgut: essays on transformation, revolution and permanence in the history of religions. Leiden: Brill, 1987. p. 288-297.

SMITH, Hazel; STARES, Paul (Ed.) Diasporas in conflict: peace-makers and peace-wreckers. Tokyo: United Nations University Press, 2007. p. 9.

SMITHER, A. D. The business of miracle working independent. London Daily Newspaper, 14 ago. 2004.

SOYSAL, Yasemin Nuho lu. Citizenship and identity: living in diasporas in post-war Europe?' Ethnic and Racial Studies, London, Routledge, v. 23, n. 1, 2000.

TÖLÖLYAN, Khachig. Restoring the logic of the sedentary to diaspora studies') In: ANTEBY-YEMENI, Lisa; BERTHOMIÈRE, William; SHEFFER, Gabriel (Ed.) Les diasporas: 2000 ans d'histoire, Rennes: Presses Universitaires de Rennes, 2005, p.138-139.

WEAVER, Alain Epp (n.d.) Constantinianism, Zionism, diaspora: toward a political theology of exile and return. Ocasional Papers, n.28, Akron, Pennsylvania, Mennonite Central Committee. Disponível em: http://mcc.org/respub/ occasional/28.html 
SOLID, DUCTILE AND LIQUID: changing notions of homeland and home in diaspora studies

\section{Robin Cohen}

Does diaspora imply a homeland? For a number of scholars who pioneered the growth of diasporic studies in the 1990s this was the sine qua non of the concept. Under the weight of social constructionist critics, who sought to deconstruct the foundational ideas of homeland and community, more complex and vaguer ideas of homeland and home emerged. These are characterized here as "solid", "ductile" and "liquid", on a diminishing scale from historical reality to postmodern virtuality. I show that all three versions of home/homeland have some historical and empirical support, but I reject the pure social construcionism. There is also some evidence that solid notions homeland are gaining increasing attention.

KEY wORDS: international migrations, diaspora, social construcionism, home/homeland, agents of development.

\section{SOLIDES, DUCTILES ET LIQUIDES: des notions qui changent, celles de foyer et de terre maternelle dans les études sur la diaspora}

\section{Robin Cohen}

La diaspora sous-entend-elle la terre maternelle? Selon certains studieux qui ont stimulé le développement des études sur la diaspora dans les années quatre-vingt-dix, il s'agissait d'une condition sine qua non pour ce concept. Sous la pression des critiques du constructionisme social qui essayaient de déconstruire les idées basiques de terre maternelle et de communauté, des notions plus complexes et indéfinies de "terre maternelle" et de "foyer" ont surgi. Celles-ci sont caractérisées ici comme "solides", "ductiles" et "liquides", par ordre décroissant, allant de la réalité historique à la virtualité post-moderne. Nous démontrons que ces trois versions de "foyer" ou de "terre maternelle" ont une base historique et empirique considérable, cependant nous refusons le simple constructionisme social. Il existe aussi des indices qui démontrent que les notions de "terre maternelle solide" sont de plus en plus dignes d'attention.

MOTS-CLÉs: migrations internationales, diaspora, constructionisme social, foyer ou terre maternelle, agents de développement.

Robin Cohen - Professor da Universidade de Oxford e Professor Honorário da Universidade de Warwick, onde foi professor de sociologia, entre 1979-2007. Foi Reitor na área de Humanidades da Universidade de Cape Town, África do Sul (2001-2003). Ensinou em várias universidades, como Ibadan, Birmingham, West Indies, Stanford, Toronto e Berkeley. É editor da coleção Global Diaspora da editora Routledge e coordenador da pesquisa sobre "Migração Mundial" em Cambridge (1995).Seus livros incluem: Labour and politics in Nigéria ([1974]1982); Endgame in South África? (1986); The new helots: migrants in the international division of labour (1987, 1993, 2003); Contested domains: debates in international labour studies (1991); Frontiers of identity: the British and the others (1994); Global diasporas: an introduction (1997, 1999, 2001, 2004); Global sociology (em co-autoria, 2000, [2001]2007) e Migration and its enemies (2006). Editou ou coeditou mais de 18 livros com foco na sociologia e política dos países em desenvolvimento, etnicidade, migração internacional, transnacionalismo e globalização. Seus trabalhos mais importantes estão traduzidos em dinamarquês, francês, alemão, grego, italiano, japonês, mandarim, português e espanhol. 